\title{
The gap between scientific evidence and food regulation: analyzing the updated Brazilian normative on the use of bioactives in food supplements
}

\author{
Renan Danielski ${ }^{a}$, Cíntia Pereira da Silva ${ }^{\mathrm{b}}$ and Adriano Costa de Camargo ${ }^{\mathrm{c}^{*}}$
}

\author{
aDepartment of Biochemistry, Memorial University of Newfoundland, St. John's, NL A1B 3X9, Canada \\ ${ }^{b}$ Food e Health Assessoria, Teresina, PI, 64049-550, Brazil \\ ${ }^{c}$ Laboratory of Antioxidants, Nutrition and Food Technology Institute, University of Chile, Santiago, Chile \\ *Corresponding author: Adriano Costa de Camargo, Laboratory of Antioxidants, Nutrition and Food Technology Institute, University of \\ Chile, Santiago, Chile. E-mail: adrianoesalq@gmail.com
}

DOI: $10.31665 /$ JFB.2020.12247

Received: December 10, 2020; Revised received \& accepted: December 31, 2020

Citation: Danielski, R., da Silva, C.P., and de Camargo, A.C. (2020). The gap between scientific evidence and food regulation: analyzing the updated Brazilian normative on the use of bioactives in food supplements. J. Food Bioact. 12: 87-96.

\begin{abstract}
The approval of new ingredients and compounds for use in food supplements is subjected to governmental regulations in many countries. In this context, there is a gap between what the scientific literature reports and how these translate into food regulation when it comes to bioactives. In this perspective piece, we analyze the case of Anvisa's Normative Instruction (NI) N 76 , which regulates food supplements in Brazil. This updated version of a previous Normative Instruction adds hyaluronic acid, boron, silicon, undenatured type II collagen, hydroxymethylbutyrate, methylsulfonylmethane, and palmitoylethanolamide to its list of approved compounds. According to the $\mathrm{NI}$, only supplements containing undenatured type II collagen are allowed to make health claims on their labels. In addition, the list does not include any substance from major bioactive groups, such as phenolic compounds. However, this might be due to the fact that the metabolic fate of phenolics has not yet been completely clarified, which could contribute to the slowing down of their approval by Anvisa. In this case, safety issues would need to be sorted out, and a direct relationship between consumption and health effect would need to be established for allowing health claims to be made. Therefore, the need for studies on the bioefficacy of bioactive compounds is imperative.
\end{abstract}

Keywords: Anvisa; Normative instruction $N^{\circ} 76$; Phenolic compounds; Hyaluronic acid; Collagen.

\section{Introduction}

The enactment of food regulations is usually based on scientific evidence. The approval process of a new ingredient and/or compound for use in food formulations may involve several steps, such as petition examination, gathering of enough and convincing scientific data, toxicity analysis, and the opinion of experts in the field, before finally reaching a consensus on whether or not the ingredient/compound could be approved. The same goes for establishing limits of usage, recommendations, claims, labelling regulations, and other details involving practical and legal aspects. Therefore, it is reasonable to consider that such procedures are time-consuming and may not move as fast as other parties expect. Nevertheless, it is common that food regulations from different countries are often somewhat different from one another. For instance, a certain compound can be legal and widely used in a specific country while in other countries the same substance may be banned. These differences reveal that each territory has its own specificities in what comes to establishing food laws and regulations, as well as their own pace of approving new compounds and banning harmful ones. This fact is especially evident in the case of 
some bioactive substances, such as phenolic compounds as already discussed by de Camargo and Lima (2019).

In Brazil, the Ministry of Health has a regulatory body (Brazil's National Health Surveillance Agency-Anvisa) that is responsible for approving and enforcing regulations for the food, cosmetics, tobacco, pharmaceuticals, health services, and medical devices, among others. Regarding food supplements, it is important to note that different countries may have specific definitions for food supplements, which will be reflected by how they will handle these products regulation-wise. For instance, in the United States, ingredients and compounds to be used in food supplements should meet the requirements of the Dietary Supplement Health and Education Act of 1994. Novel ingredients must be evaluated by the Food and Drug Administration (FDA) for approval, with the manufacturer notifying the agency 75 days prior to launching the product (Dominguez-Díaz et al., 2020). On the other hand, in Brazil, food supplements are defined as "products for oral ingestion, presented in a pharmaceutical form, aimed at supplementing the diet of healthy individuals with nutrients, bioactive substances, enzymes or probiotics, either alone or in combination" (Anvisa, 2020a).

Food supplements are regulated in Brazil by Anvisa and the inclusion of a new constituent in Anvisa's list of approved components/ingredients for use in this product category is an extensive and detail-oriented process. In general, when a petition for approval of a new constituent is received, the agency evaluates data concerning the safety of the compound and whether the compound presents any health-promoting effects, and the intake dose necessary to render beneficial effects. A second process may then take place to see whether claims regarding functional properties and health can be used to promote the product. The procedure for claim approval may proceed in parallel to the process for approval of the bioactive substance or in different timeframes. Health claim approval is contingent on availability of sufficient data to demonstrate that there is a direct relationship between consumption and positive health outcome (Anvisa, 2020b).

Anvisa's recently published Normative Instruction (NI) $\mathrm{N}^{\circ} 76$ of November $5^{\text {th }}, 2020$ updates the list of ingredients and compounds allowed in food supplement formulations, as well as their limits of usage, claims, and labelling requirements. The list includes several nutrients (proteins, lipids, minerals, vitamins), enzymes, probiotics, and bioactive compounds (Anvisa, 2020c), with the latter two being the focus of the present analysis. It is noteworthy that this specific NI is an addition to the Normative Instruction $\mathrm{N}^{\circ} 28$ from July $26^{\text {th }}$, 2018, which was reviewed by de Camargo and Lima (2019), with an emphasis on phenolic compounds.

Regarding bioactive compounds, the NI 76 addresses only ingredients and compounds used in food supplements not intended for breastfeeding women ( 0 to 12 months) and children aged between 1 and 3 years. However, an update from December 2020 establishes limits of use for folic acid in supplements intended for children and teenagers between 1 and 18 years of age (Brazil, 2020). Table 1 provides the list of newly added compounds with their limits of usage according to age and condition, as well as approved claims. According to the labelling requirements, products containing the compounds in Table 1 must display the warning "This product should not be consumed by pregnant and lactating women and children."

A total of 15 bioactive substances have been allowed by IN 76 to be incorporated as ingredients in food supplements; these are: hyaluronic acid, sodium hyaluronate obtained by Streptococcus zooepidemicus assisted fermentation, rooster comb extract (Gallus gallus), boron, sodium tetraborate decahydrate, type 2 collagen, chicken collagen with undenatured type II collagen, phosphatidylserine, phosphatidylserine from soy lecithin, hydroxymethylbutyrate, calcium hydroxymethylbutyrate, methylsulfonylmethane,

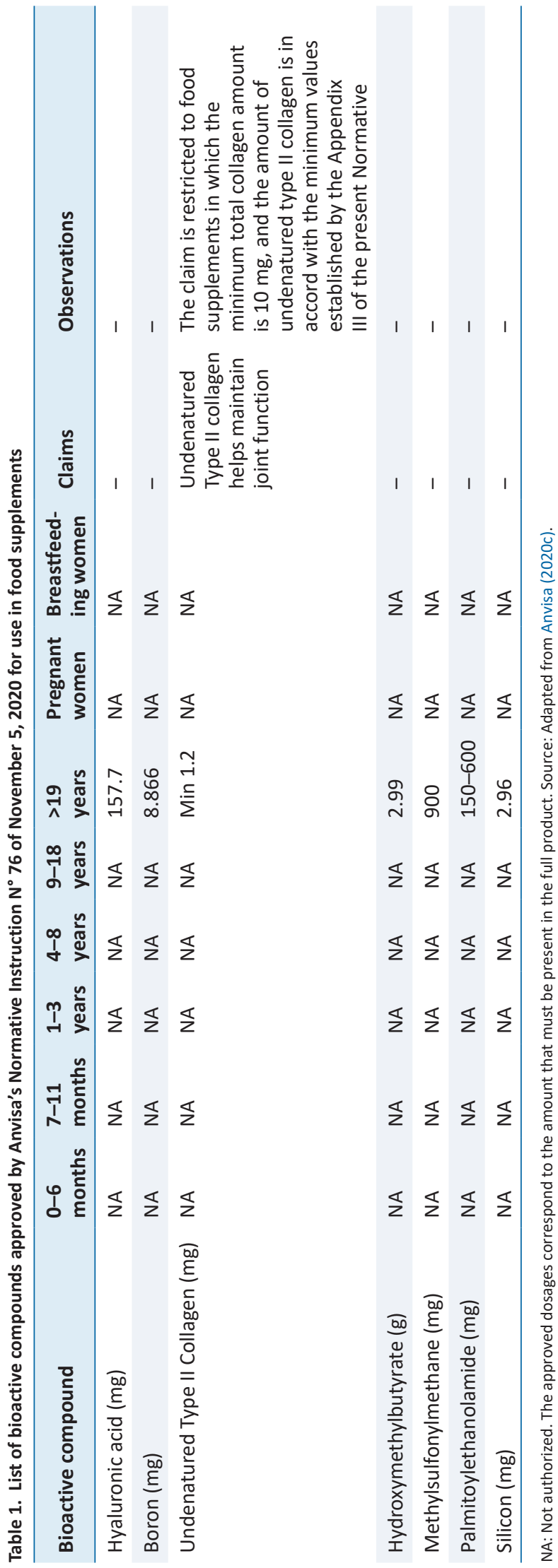


silicon, orthosilicic acid stabilized with choline chloride, and palmitoylethanolamide (Anvisa, 2020c).

However, it is important to note that some promising bioactive classes, such as phenolic compounds, have not been addressed by NI 76, leading to no additional improvements in this aspect when compared with NI 28 (Anvisa, 2020c). This is especially remarkable since this bioactive class of compounds is backed by mounting scientific evidence about their heath-promoting benefits, such as antioxidant, cardioprotective, anticancer, and anti-inflammatory properties (de Camargo et al., 2018), deeming them suitable for possible use as food supplement. Another gap that remains since NI 28 is the lack of approved sources of bioactive compounds that are widely available in Brazil. As pointed out by de Camargo and Lima (2019), NI 28 approves the incorporation of rutin into food supplements, but fails to include orange peel and other rutin-rich feedstocks that are widely available in the country as a rich source of this compound. The same comment could be made for chlorogenic acid, proanthocyanidins, tocopherols and tocotrienols. In this situation, and as far as we know, no petitions from manufacturers requesting the use of these ingredients were sent to the agency as evaluations happen through a petition-based system. Therefore, the food industry is a key player in what may be added to the list of bioactive compounds under existing regulations in Brazil. The individual compounds listed in the latest approved bioactives in Brazil are discussed below.

\section{Hyaluronic acid}

Hyaluronic acid is an anionic and non-sulfated carbohydrate present in the connective, epithelial, and neural tissues. Its structure consists of several disaccharide molecules bonded through $\beta-1,4$ glycosidic linkages, with the repeating structure $[(1 \rightarrow 3)-\beta-d-$ GlcNAc- $(1 \rightarrow 4)-\beta-d-G l c A-]$. The main biological function of hyaluronic acid is to bind water, acting as a lubricant for the joints and muscles. Due to this characteristic, hyaluronic acid may also be perceived as component for use in cosmetics, more specifically in moisturizers. As a naturally occurring substance in all living organisms, hyaluronic acid has also been used in clinical applications, such as the supplementation of joint fluid in arthritis, eyesupporting structures during eye surgery, and healing aid of surgical wounds (Necas et al., 2008).

Besides its clinical applications, hyaluronic acid is also known to display in vitro and in vivo antioxidant activity. Ke et al. (2011) demonstrated that low-molecular-weight hyaluronic acid produced from its high-molecular-weight counterpart was able to effectively inhibit lipid peroxidation and scavenge superoxide anion, hydroxyl, and 1,1-diphenyl-2-picryldydrazyl (DPPH) radicals. When administered orally to immunosuppressed mice, hyaluronic acid increased the activity of endogenous antioxidant enzymes, namely superoxide dismutase, catalase, and glutathione peroxidase.

The European Food Safety Authority (EFSA) released a scientific opinion in 2009 deeming hyaluronic acid an authorized component for use in food formulations. The report highlighted that the compound has been sufficiently characterized in the literature and proposed claims regarding the improvement of joint health, by contributing to joint mobility and lubrication. The report also established limits of intake that should not exceed $100 \mathrm{mg}$ per day (EFSA, 2009a). Anvisa's NI 76 indicates that $157.7 \mathrm{mg}$ should be the compound's limit of usage in food supplements marketed to adults (Table 1), but it does not bring any approved claims and sources for procuring hyaluronic acid. For claim approval, a direct relationship between intake and health effect would need to be attested by Anvisa's regulatory process. The only ingredient/compound in NI 76 with approved claims at this time is undenatured type II collagen.

Soybean and soy-derived products (tofu, soy milk, soy yogurt) are well-known sources of hyaluronic acid. Among the leading soybean producers in the world (Statista, 2020) the availability of this source is plenty in Brazil and it could serve as an ingredient for obtaining the approved compound. Pan et al. (2015) proposed the use of agro-industrial by-products widely available in Brazil (sugarcane molasses and juice, soy molasses, soy protein, corn steep liquor, and whey protein) for procurement of hyaluronic acid through Streptococcus zooepidemicus fermentation. However, the use of such sources for the extraction of hyaluronic acid was not addressed by NI 76, a gap that needs to be filled by the food industry (Table 1).

\section{Boron and silicon}

Boron and silicon are trace elements naturally occurring in food and have also been included in the NI 76 as approved components of food supplements. Boron is present in fruits (e.g, peaches, grape, apple, orange), vegetables (e.g., lettuce, broccoli), milk, coffee and tea (National Institute of Health, 2020), while silicon can be found in raisins, green beans, high-bran cereal, whole grain bread, beer, and red wine, among others (Charles, Kenneth, and Joshua, 2013). Both substances have been perceived as bioactives for promoting health such as bone growth and maintenance, protection of the central nervous system, reduction of arthritis and cancer development (Nielsen, 2014a) in the case of boron, while silicon has been associated with improving bone and connective tissue health, as well as immune and inflammatory response (Nielsen, 2014b).

A clinical trial (Miljkovic et al., 2009) involving 20 subjects affected by osteoarthritis found that boron supplementation of 6 $\mathrm{mg} / \mathrm{d}$ as calcium fructoborate, found in fruits and vegetables, was able to mitigate the symptoms associated with this condition, with $80 \%$ of the subjects reporting to have reduced or abandoned the use of painkiller medication. Another human study (Scorei and Rotaru, 2011) showed that the consumption of margarine-enriched boron ( $226 \mathrm{mg} / \mathrm{d}$ of calcium fructoborate) for six months improved bone density in $66 \%$ of osteoporosis patients.

The proposed action mechanism of boron responsible for its health benefits involves the formation of ester complexes between boric acid and hydroxyl groups of adjacent compounds, especially ribose, a component of adenosine base. This ability increases the affinity of biologically relevant molecules for boron in animal tissues. Another proposed mechanism is the formation of diester borate complexes with phosphoinositides, glycoproteins, and glycolipids in cellular membranes, acting as calcium chelators and redox modifiers, affecting membrane integrity and function (Nielsen, 2014a).

In the United States, boron is largely used in dietary supplements at $0.15-6 \mathrm{mg}$, either alone or in combination with other nutrients (National Institute of Health, 2020). Anvisa's NI 76 establishes $8.866 \mathrm{mg}$ in the final product ( $>19$ yeas old) as the limit for boron incorporation into food supplements (Table 1). EFSA (2009b) has concluded that boron is sufficiently characterized and hence approved its use as a food constituent with claims related to the amelioration of joint and bone health.

Silicon is believed to perform a structural or binding role in the connective tissue, binding to it in abundant concentrations. This hypothesis is backed by the fact that silicon is capable of forming complexes with polyols having a minimum of four hydroxyl groups, which are present in glycosaminoglycans, mucopolysaccharides, and collagen. Such molecules are involved in the formation and stabilization of the connective tissue as well as bone formation. Another hypothesis is that silicon may positively affect 
the absorption and utilization of other minerals related to bone metabolism and inflammatory response. According to epidemiological evidence, an intake of $25 \mathrm{mg} / \mathrm{d}$ of silicon is necessary for promoting bone health (Nielsen, 2014b).

EFSA approves the use of silicon as a food constituent. The agency has established that the amount of silicon in food supplements depends on the target and the form it is incorporated in the formulation. Claims related to joint, bone, and skin health are approved to be used in labels, as well as claims about cardiovascular and brain health (EFSA, 2011). Incorporation of silicon in food supplements is limited to $2.96 \mathrm{mg}$ for adults (Table 1).

\section{Undenatured type II collagen}

Collagen is a structural protein found abundantly in the connective tissues of the mammals. This protein is characterized by a triple helix formed by three polypeptide chains, containing around 1,000 amino acids in each chain, with approximately $300 \mathrm{kDa}$ molecular weight. Among the 30 existing types of collagen, type I is predominant, representing over $90 \%$ of all collagen present in the body. Nevertheless, undenatured type II collagen (UC-II), a component of cartilage, has gained attention due to its positive effects on osteoarthritis and joint health (Gencoglu et al., 2020).

In a rat model of osteoarthritis, supplementation of $0.66 \mathrm{mg} / \mathrm{kg}$ of UC-II for 8 weeks was examined by Bagi et al. (2017). These researchers showed that UC-II was able to preserve the integrity of cancellous bone at tibial metaphysis, as well as limiting excessive formation of osteophyte and degradation of articular cartilage. Cartilage degradation was further studied in a randomized controlled trial with 39 patients diagnosed with knee osteoarthritis (Bakilan et al., 2016). The treatment involved administration of 10 $\mathrm{mg}$ /day of UC-II for three months. Although biochemical markers did not detect improvements regarding cartilage degradation, significant enhancement was achieved for joint pain and function in comparison with acetaminophen treatment.

Some proposed mechanisms of action for the amelioration of joint health caused by UC-II include the recognition of UC-II by Treg (regulatory T) cells, active immune cells that secrete anti-inflammatory mediators that help diminish joint inflammation whilst promoting cartilage repair. This is possible due to collagen's oral tolerance, an immune process trigged by the body's recognition of innocuous compounds and potentially harmful substances (Bagi et al., 2017).

Although there is no established upper limit of usage for UC-II in Anvisa's NI 76 (Table 1), this is the only component with approved health claims. According to the regulation, the claim "Undenatured Type II collagen helps maintain joint function" can be displayed on the label of food supplements containing a minimum of $10 \mathrm{mg}$ of UC-II. The claim is in accordance with the scientific literature on health benefits related to UC-II.

\section{Hydroxymethylbutyrate, methylsulfonylmethane, and palmi- toylethanolamide}

Hydroxymethylbutyrate (HMB), a leucine metabolite naturally produced in the human body, is largely used as food supplement for cancer patients and people living with HIV who are experiencing weight loss. A systematic review conducted by Asghari Hanjani et al. (2018) concluded that the use of HMB in combination with arginine and glutamine improves lean mass, weight, and immune function in weight-compromised patients. According to Molfino et al. (2013), HMB prevents muscle mass degradation by a number of pathways, including the attenuation of protein kinase R (PKR), AKT, the scavenging of reactive oxygen species, and decreasing the activity of caspase 3 and 8 .

Methylsulfonylmethane (MSM) is a naturally occurring organosulfur compound, also widely used as dietary supplement. Food sources of MSM include fruits, vegetables, grains, beer, wine, coffee, tea, and cow's milk. In vitro and in vivo studies have associated the intake of MSM with anti-inflammatory, anticarcinogenic, and antioxidant effects (Butawan et al., 2017). EFSA approved the use of MSM as a food constituent and allows claims involving the improvement and maintenance of joint health in products containing this compound (EFSA, 2009c).

Palmitoylethanolamide (PEA) is an endogenous fatty acid amide synthesized by microglia and mast cells, and provides anti-inflammation and neuroprotective effects. PEA is believed to maintain homeostasis through mediating the resolution of inflammatory processes, thus controlling neuroinflammation, and helping prevent and ameliorate symptoms of neurodegenerative diseases such as Alzheimer's (Cordaro et al., 2020).

Hydroxymethylbutyrate, methylsulfonylmethane, and palmitoylethanolamide can be used as food supplements commercialized in Brazil as long as they respect the limits of usage established by NI 76 (Table 1).

\section{Probiotics}

Anvisa defines probiotics as "Viable microorganisms that when taken in adequate amounts, provide health benefits. These microorganisms belong to different genus and species (both bacteria and yeasts) and have been associated with several health benefits" (Anvisa, 2020d). Besides improving gut health, probiotics have been associated with a myriad of other health-promoting effects, such as modifying immune response against inflammatory diseases, inhibiting metabolic syndrome-related ailments in pre-diabetic adults, reducing neurodegenerative damage, among others (Roobab et al., 2020). With that being said, the agency's process to approve new probiotics for food supplements is based on the evidence that a certain microorganism is able to effectively improve human health. Clinical trials are the foundation for the inclusion of newly approved probiotics into the regulation, once the results of in vitro studies, although essential to characterize microorganisms, are not necessarily reproducible in vivo, especially in human subjects (Anvisa, 2017).

According to Anvisa, the request for probiotics approval should take into consideration the type of claim being pursued - general or specific. A general claim needs to be backed by at least one clinical study showing adequate evidence level for the said benefit, with a well-established mechanism of action. In this case, the agency also analyzes evidence other than clinical, such as in vitro and animal studies. However, if a manufacturer wants to make specific claims for their probiotic, a minimum of two clinical studies is required, showing the efficacy towards the claimed benefit. For this type of claim, the process is completely focused on clinical evidence (Anvisa, 2020d; Anvisa, 2017).

In general, a probiotic to be used in food supplements must have been properly identified as being safe for consumption and having displayed efficacy towards gastrointestinal (general claim) and other health-promoting benefits (specific claim). IN 76 has included a total of 12 new probiotics/probiotic mixtures for use in food supplements (Table 2). All of them carry approved claims and an extensive list of minimum usage limits established, separated by age group. According to the normative instruction, the claims can 


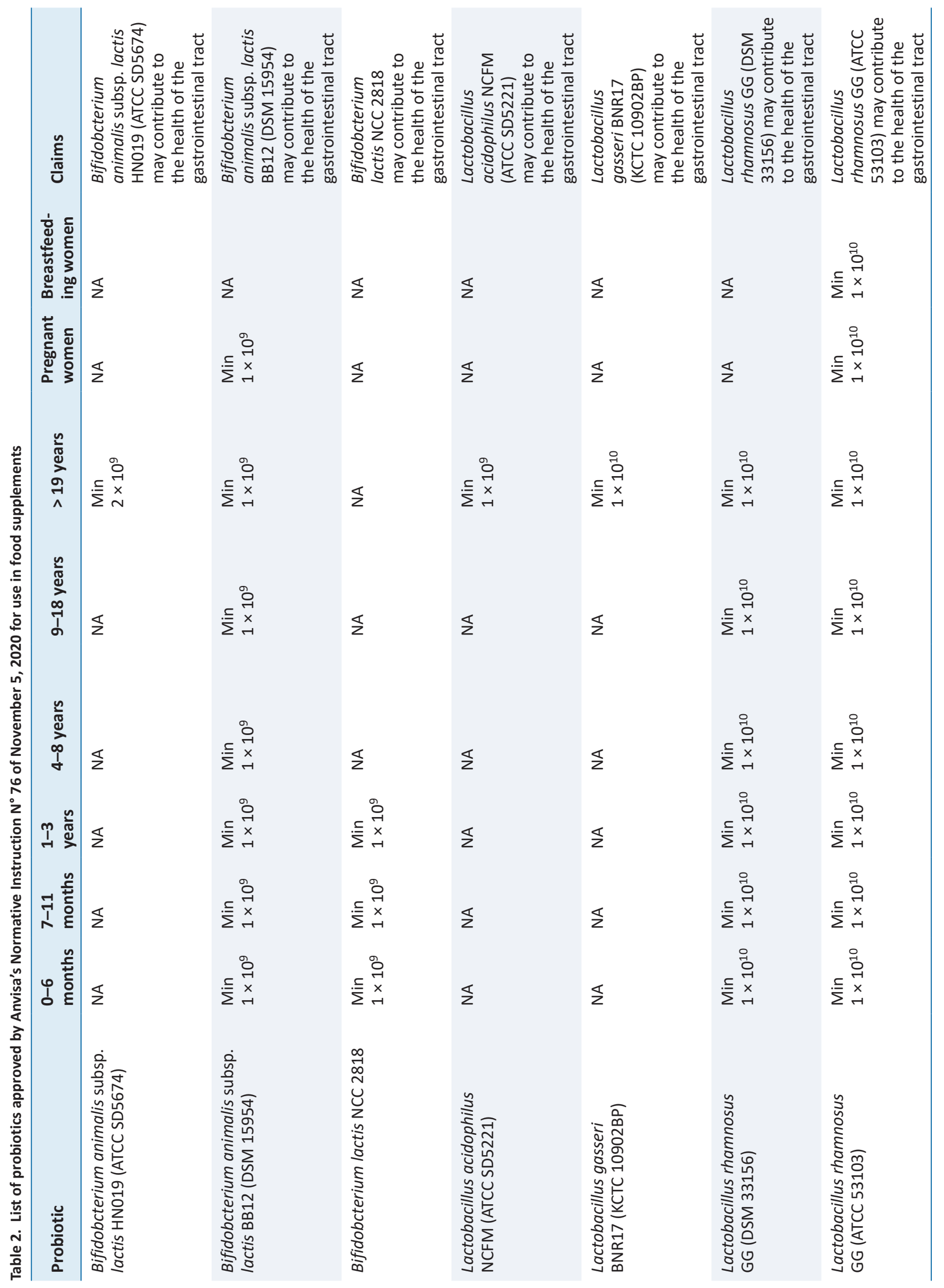




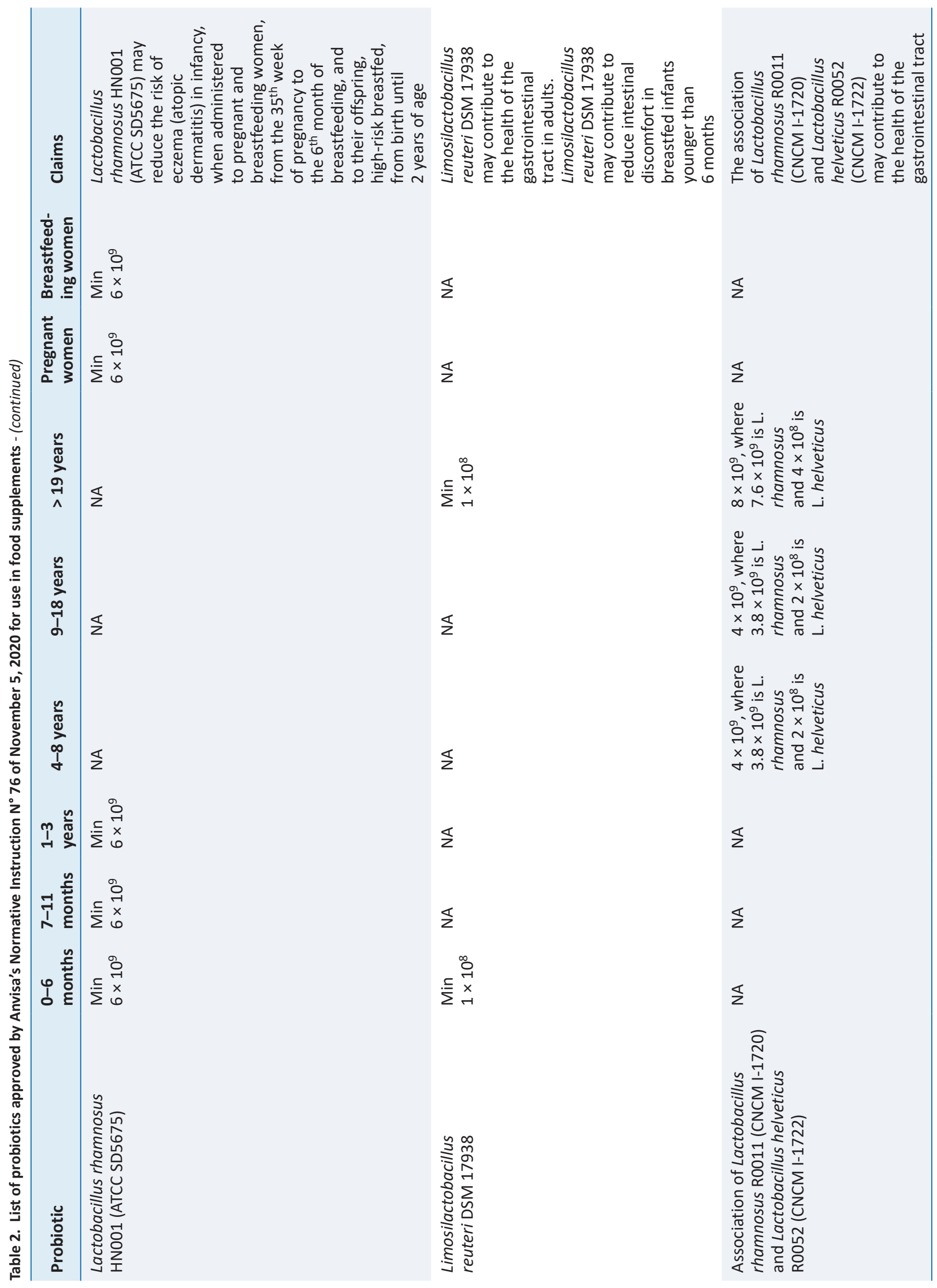




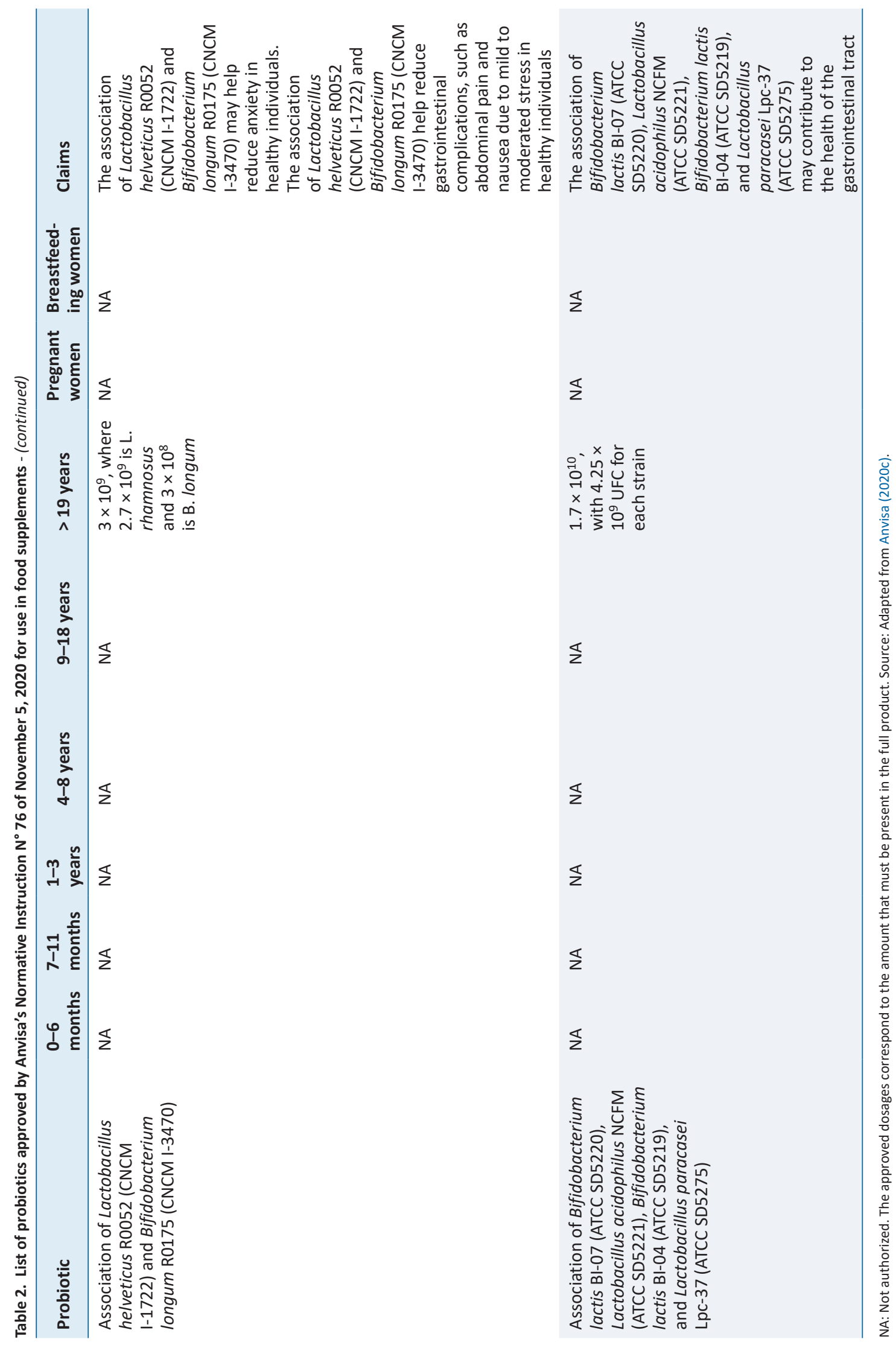


only be made if the supplement provides the minimum established level for the efficacy of the probiotic used.

The inclusion of a high number of probiotics in the Brazilian legislation is an indicator of the importance of food manufacturers working closely with academia in order to reduce any gaps in the regulation.

\section{Bioactive compounds not included in NI 76}

In recent decades, phenolics have become one of the most prominent bioactive classes of compounds. This large group of phytochemicals is vastly concentrated in fruits, vegetables, nuts, cereals, herbs, and spices, among other plant sources. The basic structure of a phenolic compound consists of at least one hydroxylated benzene ring. Structural differences determine their classification into subgroups, with flavonoids, phenolic acids, and tannins (hydrolysable and condensed) being the major ones. In their natural sources, phenolics can be present as soluble (free, esterified, and/or etherified) and insoluble-bound (associated with fiber, cellulose, pectin, and protein) compounds (de Camargo et al., 2018).

The main biologically relevant characteristic associated with phenolics is their antioxidant capacity, which can be manifested through different mechanisms, such as donation of hydrogen atoms to free radicals, interrupting oxidation chain reactions, and ability to reduce and/or chelate transition metals, which are prooxidant factors (Shahidi et al., 2019). Due to their antioxidant activity, phenolics have shown in vitro and in vivo evidence of numerous potential health-promoting effects, including anti-inflammatory activity (Colombo et al., 2019; Zhang et al., 2019), antimicrobial potential (de Camargo et al., 2017), prevention of some types of cancer (Ayoub et al., 2017), reduced risk of cardiovascular diseases (Lutz et al., 2019), prevention and management of type 2 diabetes (Pinaffi et al., 2020), and diminished risk of neurodegenerative diseases (Hanafy et al., 2020; Taslimi et al., 2019), among others.

Notwithstanding, the fate of phenolic compounds upon ingestion and aspects related to their absorption, metabolism, and bioavailability are not yet fully understood. It is also reasonable to expect that these aspects will not be the same for every compound within such a diverse group. The state in which the phenolics are found in the food matrix, association with other molecules, and structural modification through the gastrointestinal tract will influence their bioaccessibility and bioavailability. In addition, phenolic compounds are known to interact with each other in additive, synergistic and antagonistic manners, which makes it harder to predict how a specific compound will behave in terms of biological activity in different food systems (Shahidi and Peng, 2018).

The NI 28 only included rutin, chlorogenic acid, and proanthocyanidins in its approved list of components to be used in food supplements. However, this additional list of approved bioactives of NI 76 did not include any other phenolic compounds (de Camargo and Lima, 2019). The key to understand this gap between regulation and scientific evidence supporting the benefits of phenolic consumption may lie in the fact that there is a limited number of epidemiological studies evidencing the efficacy of some phenolic compounds from Brazilian native sources and/or important local commodities on human health. Anvisa's process for approving new constituents is based upon the availability of data clearly demonstrating the relationship between the consumption of a certain substance and its effect on claimed benefits. Furthermore, the safety of substances incorporated into food products and supplements is a major concern for regulatory agencies, including Anvisa (Low et al., 2017). Therefore, there is a need for further clarification of the fate of phenolic compounds in the gastrointestinal tract, as well as determination of the threshold necessary for each phenolic to achieve health promotion.

\section{Conclusions}

Scientific evidence and food regulation enactment do not always move at the same pace. The complexity of approving new substances to be used in food supplements may vary according to the country. In Brazil, the process, regulated by Anvisa, involves the gathering of sufficient scientific proof demonstrating the cause/effect relationship of a designated compound. Therefore, some classes of bioactive compounds can be left out of the list of approved ingredients/constituents due to the lack of sufficient clarification about their metabolic fate, absorption rate, and biavailability aspects. This shows the importance of conducting in vivo studies, especially human trials, when researching the potential healthpromoting benefits of a bioactive substance.

Besides, Anvisa's Normative Instruction $N^{\circ} 76$ expands the list of approved bioactive compounds for use in food supplements, including substances that have largely been used in this type of product in the United States and European countries. Additionally, an extensive list of newly incorporated probiotics for use in food supplements has been included, all of them with approved health claims addressing the benefits that probiotic consumption can bring to digestive health.

Nevertheless, some aspects have not been improved since the publication of the previous Normative Instruction addressing bioactives for food supplements in Brazil, including the lack of approved health claims for most of the compounds and absence of natural sources available in the country for their procurement. This highlights the key role of the food industry when it comes to the approval of new ingredients to be used in food supplements. Thus, a close relationship between the scientific community and the industry is essential in order to accumulate relevant data that will back up the regulation of new bioactives.

\section{References}

Anvisa. (2017). Probiotics: Establishing the list of probiotic strains. http:// antigo.anvisa.gov.br/documents/3845226/0/An\%C3\%A1lise+das+L inhagens+de+Probi\%C3\%B3ticos_23042018.pdf/6e37da13-21514330-85b0-0f449dbb0e95. Accessed 7 Dec. 2020.

Anvisa. (2020a). Food supplements. https://www.gov.br/anvisa/pt-br/ acessoainformacao/perguntasfrequentes/alimentos/suplementosalimentares. Accessed 16 Nov. 2020.

Anvisa.(2020b).Listofingredients(constituents)authorizedforuseinfoodsupplements. https://www.gov.br/anvisa/pt-br/assuntos/alimentos/suple mentos-alimentares/ingredientes. Accessed 16 Nov. 2020.

Anvisa. (2020c). Normative Instruction - NI N 76, of November 5th, 2020. https://www.in.gov.br/en/web/dou/-/instrucao-normativa-in-n76-de-5-de-novembro-de-2020-287508490. Accessed 16 Nov. 2020.

Anvisa. (2020d). Procedural instruction guide for probiotics evaluation for use in foods. https://www.gov.br/anvisa/pt-br/assuntos/noticias-anvisa/2019/guia-orienta-sobre-instrucao-processual-de-probioticos. Accessed 7 Dec. 2020.

Asghari Hanjani, N., Farsi, F., Sepidarkish, M., Omidi, A., Ardehali, S.H., Akbari-Fakhrabadi, M., and Heshmati, J. (2018). Effect of supplementation with a combination of L-arginine, L-glutamine, and hydroxy methyl butyrate on cachexia: A systematic review. J. Food Biochem. 42(6): e12636. doi:10.1111/jfbc.12636.

Ayoub, N.M., Siddique, A.B., Ebrahim, H.Y., Mohyeldin, M.M., and El Sayed, K.A. (2017). The olive oil phenolic (-)-oleocanthal modulates estro- 
gen receptor expression in luminal breast cancer in vitro and in vivo and synergizes with tamoxifen treatment. Eur. J. Pharmacol. 810 100-111. doi:10.1016/j.ejphar.2017.06.019.

Bagi, C.M., Berryman, E.R., Teo, S., and Lane, N.E. (2017). Oral adminis tration of undenatured native chicken type II collagen (UC-II) diminished deterioration of articular cartilage in a rat model of osteoarthritis (OA). Osteoarthr. Cartil. 25(12): 2080-2090. doi:10.1016/j. joca.2017.08.013.

Bakilan, F., Armagan, O., Ozgen, M., Tascioglu, F., Bolluk, O., and Alatas, O. (2016). Effects of Native Type II Collagen Treatment on Knee Osteoarthritis: A Randomized Controlled Trial/Diz Osteoartritli Hastalarda Nativ Tip 2 Kollajen Tedavisinin Degerlendirilmesi: Randomize Kontrollu Calisma. Eurasian J. Med. 48(2): 95. doi:10.5152/eurasianjmed.2015.15030.

Brazil. (2020). Retificação do ANEXO II (CONSTITUINTES INCLUÍDOS NA "LISTA DE CONTITUINTES AUTORIZADOS PARA USO EM SUPLEMENTOS ALIMENTARES INDICADOS PARA LACTENTES (0 A 12 MESES) OU CRIANÇAS DE PRIMEIRA INFÂNCIA (1 A 3 ANOS)") da Instrução Normativa - IN no 76, de 5 de novembro de 2020, de 29 de dezembro de 2020. https://www.in.gov.br/web/dou/-/retificacao-296824474. Accessed 18 January 2021.

Butawan, M., Benjamin, R., and Bloomer, R. (2017). Methylsulfonylmethane: Applications and Safety of a Novel Dietary Supplement. Nutrients 9(3): 290. doi:10.3390/nu9030290.

Charles, T.P., Kenneth, J.K., and Joshua, R.L. (2013). Silicon: A Review of Its Potential Role in the Prevention and Treatment of Postmenopausal Osteoporosis. Int. J. Endocrinol. 2013: 316783-316786. doi:10.1155/2013/316783.

Colombo, F., Di Lorenzo, C., Regazzoni, L., Fumagalli, M., Sangiovanni, E., Peres de Sousa, L., Bavaresco, L., Tomasi, D., Bosso, A., Aldini, G. Restani, P., and Dell'Agli, M. (2019). Phenolic profiles and anti-inflammatory activities of sixteen table grape ( Vitis vinifera L.) varieties. Food Funct. 10(4): 1797-1807. doi:10.1039/c8fo02175a.

Cordaro, M., Cuzzocrea, S., and Crupi, R. (2020). An Update of Palmitoylethanolamide and Luteolin Effects in Preclinical and Clinical Studies of Neuroinflammatory Events. Antioxidants 9(3): 216. doi:10.3390/ antiox9030216.

de Camargo, A.C., and Lima, R.S. (2019). A perspective on phenolic compounds, their potential health benefits, and international regulations: The revised Brazilian normative on food supplements. J. Food Bioact. 7: 7-17. doi:10.31665/JFB.2019.7193.

de Camargo, A.C., Regitano-d'Arce, M.A.B., Rasera, G.B., Canniatti-Brazaca, S.G., do Prado-Silva, L., Alvarenga, V.O., Sant'Ana, A.S., and Shahidi, F. (2017). Phenolic acids and flavonoids of peanut by-products: Antioxidant capacity and antimicrobial effects. Food Chem. 237: 538-544.

De Camargo, A.C., Schwember, A.R., Parada, R., Garcia, S., Maróstica Júnior, M.R., Franchin, M., Regitano-d'Arce, M.A.B., and Shahidi, F. (2018). Opinion on the Hurdles and Potential Health Benefits in Value-Added Use of Plant Food Processing By-Products as Sources of Phenolic Compounds. Int. J. Mol. Sci. 19(11): 3498. doi:10.3390/ijms19113498.

Dominguez-Díaz, L., Fernández-Ruiz, V., and Cámara, M. (2020). The frontier between nutrition and pharma: The international regulatory framework of functional foods, food supplements and nutraceuticals. Crit. Rev. Food Sci. Nutr. 60(10): 1738-1746

EFSA. (2009a). Scientific Opinion on the substantiation of health claims related to hyaluronic acid and maintenance of joints (ID 1572, $1731,1932,3132$ ) pursuant to Article 13(1) of Regulation (EC) No 1924/2006. https://efsa.onlinelibrary.wiley.com/doi/epdf/10.2903/j. efsa.2009.1266. Accessed 16 Nov. 2020.

EFSA. (2009b). Scientific Opinion on the substantiation of health claims related to boron and maintenance of bone (ID 218, 219) and maintenance of joints (ID 219, 220) pursuant to Article 13(1) of Regulation (EC) No 1924/2006. https://efsa.onlinelibrary.wiley.com/doi/ epdf/10.2903/j.efsa.2009.1261. Accessed 16 Nov. 2020.

EFSA. (2009c). Scientific Opinion on the substantiation of health claims related to methylsulfonylmethane alone or in combination with glucosamine hydrochloride and maintenance of joints (ID 395, 1616, 1617) pursuant to Article 13(1) of Regulation (EC) No 1924/2006 https://efsa.onlinelibrary.wiley.com/doi/epdf/10.2903/j.efsa. 2009.1268. Accessed 16 Nov. 2020.

EFSA. (2011). Scientific Opinion on the substantiation of health claims related to silicon and protection against aluminium accumulation in the brain (ID 290), "cardiovascular health" (ID 289), forming a protective coat on the mucous membrane of the stomach (ID 345), neutralisation of gastric acid (ID 345), contribution to normal formation of collagen and connective tissue (ID 287, 288, 333, 334, 335, $1405,1652,1718,1719,1945)$, maintenance of normal bone (ID $287,335,1652,1718,1945)$, maintenance of normal joints (ID 1405 , $1652,1945)$, maintenance of normal appearance and elasticity of the skin (ID 288, 333), and contribution to normal formation of hair and nails (ID 334, 1652, 1719) pursuant to Article 13(1) of Regulation (EC) No 1924/2006. https://efsa.onlinelibrary.wiley.com/doi/ epdf/10.2903/j.efsa.2011.2259. Accessed 16 Nov. 2020.

Gencoglu, H., Orhan, C., Sahin, E., and Sahin, K. (2020). Undenatured Type II Collagen (UC-II) in Joint Health and Disease: A Review on the Current Knowledge of Companion Animals. Animals (Basel) 10(4): 697. doi:10.3390/ani10040697.

Hanafy, D.M., Burrows, G.E., Prenzler, P.D., and Hill, R.A. (2020). Potential Role of Phenolic Extracts of Mentha in Managing Oxidative Stress and Alzheimer's Disease. Antioxidants 9(7): 631. doi:10.3390/antiox9070631.

Ke, C., Sun, L., Qiao, D., Wang, D., and Zeng, X. (2011). Antioxidant acitivity of low molecular weight hyaluronic acid. Food Chem. Toxicol. 49(10): 2670-2675. doi:10.1016/j.fct.2011.07.020.

Low, T.Y., Wong, K.O., Yap, A.L., De Haan, L.H., and Rietjens, I.M. (2017) The regulatory framework across international jurisdictions for risks associated with consumption of botanical food supplements. Compr. Rev. Food Sci. Food Saf. 16(5): 821-834.

Lutz, M., Fuentes, E., Ávila, F., Alarcón, M., and Palomo, I. (2019). Roles of Phenolic Compounds in the Reduction of Risk Factors of Cardiovascular Diseases. Molecules (Basel, Switzerland) 24(2): 366. doi:10.3390/ molecules24020366.

Miljkovic, D., Scorei, R.I., Cimpoia u, V.M., and Scorei, I.D. (2009). Calcium Fructoborate: Plant-Based Dietary Boron for Human Nutrition. J. Diet. Suppl. 6(3): 211-226. doi:10.1080/19390210903070772.

Molfino, A., Gioia, G., Rossi Fanelli, F., and Muscaritoli, M. (2013). Betahydroxy-beta-methylbutyrate supplementation in health and disease: a systematic review of randomized trials. Amino Acids 45(6): 1273-1292. doi:10.1007/s00726-013-1592-z.

National Institute of Health. (2020). https://ods.od.nih.gov/factsheets/ Boron-HealthProfessional/\#en2. Accessed 18 Nov. 2020.

Necas, J., Bartosikova, L., Brauner, P., and Kolar, J. (2008). Hyaluronic acid (hyaluronan): a review. Vet. Med. 53(8): 397-411.

Nielsen, F.H. (2014a). Update on human health effects of boron. JTEBF 28(4): 383-387. doi:10.1016/j.jtemb.2014.06.023.

Nielsen, F.H. (2014b). Update on the possible nutritional importance of silicon. JTEBF 28(4): 379-382. doi:10.1016/j.jtemb.2014.06.024.

Pan, N.C., Vignoli, J.A., Baldo, C., Pereira, H.C.B., Silva, R.S.S.F., and Celligoi, M.A.P.C. (2015). Agroindustrial byproducts for the production of hyaluronic acid by Streptococcus zooepidemicus ATCC 39920. Int. J. Sci. Res. 4(4): 114-118.

Pinaffi, A.C.D.C., Sampaio, G.R., Soares, M.J., Shahidi, F., de Camargo, A.C., and Torres, E.A.F.S. (2020). Insoluble-Bound Polyphenols Released from Guarana Powder: Inhibition of Alpha-Glucosidase and Proanthocyanidin Profile. Molecules (Basel, Switzerland) 25(3): 679. doi:10.3390/molecules25030679.

Roobab, U., Batool, Z., Manzoor, M.F., Shabbir, M.A., Khan, M.R., and Aadil, R.M. (2020). Sources, formulations, advanced delivery and health benefits of probiotics. Curr. Opin. Food Sci. 32: 17-28.

Scorei, R.I., and Rotaru, P. (2011). Calcium Fructoborate-Potential Antiinflammatory Agent. Biol. Trace Elem. Res. 143(3): 1223-1238. doi:10.1007/s12011-011-8972-6.

Shahidi, F., and Peng, H. (2018). Bioaccessibility and bioavailability of phenolic compounds. J. Food Bioact. 4: 11-68.

Shahidi, F., Varatharajan, V., Oh, W.Y., and Peng, H. (2019). Phenolic compounds in agri-food by-products, their bioavailability and health effects. J. Food Bioact. 5(1): 57-119.

Statista. (2020). Leading soybean producing countries worldwide from 2012/13 to 2019/20. https://www.statista.com/statistics/263926/ soybean-production-in-selected-countries-since-1980/. Accessed 18 Nov. 2020.

Taslimi, P., Köksal, E., Gören, A.C., Bursal, E., Aras, A., Kılıç, Ö., Alwasel, 
S., and Gülçin, İ. (2019). Anti-Alzheimer, antidiabetic and antioxidant potential of Satureja cuneifolia and analysis of its phenolic contents by LC-MS/MS. Arab. J. Chem. 13(3): 4528-4537. doi:10.1016/j.arabjc. 2019.10.002.

Zhang, Q., Gonzalez de Mejia, E., Luna-Vital, D., Tao, T., Chandrasekaran,
S., Chatham, L., Juvik, J., Singh, V., and Kumar, D. (2019). Relationship of phenolic composition of selected purple maize (Zea mays L.) genotypes with their anti-inflammatory, anti-adipogenic and antidiabetic potential. Food Chem. 289: 739-750. doi:10.1016/j.foodchem.2019.03.116. 